DOI 10.5216/ia.v46i2.67348

\title{
OS DIREITOS HUMANOS DAS CRIANÇAS REFUGIADAS NO BRASIL DO SÉCULO XXI: INTERFACES EDUCACIONAIS
}

\author{
Giovana de CARVALHo FlorênCIO \\ Universidade Federal da Grande Dourados (UFGD), Dourados, Mato Grosso do Sul, Brasil
}

\begin{abstract}
Resumo: A presente pesquisa trata sobre a aplicação dos Regimes Internacionais nos Direitos Humanos das Crianças Refugiadas no Brasil do século XXI e suas implicações na seara educacional. Nesse diapasão, objetiva entender a consolidação e internalização dos direitos básicos educacionais visando à integração social dessas crianças. Apresenta-se, ainda, como uma pesquisa bibliográfica fundamentada na pesquisa documental da área, isto é, legislação, doutrinas e tratados internacionais. Por fim, concluiu-se que o país tem aplicado juridicamente os acordos internacionais em um aspecto formal, contudo mostra-se pouco desenvolvido no quesito das políticas públicas, da legislação unificada e da efetiva proteção desses indivíduos.
\end{abstract}

Palavras-chave: Refugiados. Crianças. Direitos Humanos. Educação.

\section{INTRODUÇÃO}

A presente pesquisa trata sobre a situação educacional das crianças refugiadas, tendo como panorama os Direitos Humanos aplicados no Brasil, com enfoque no século XXI. Seu objetivo é entender a consolidação e internalização desses direitos básicos educacionais visando à integração social dessas pessoas. Portanto, realizou-se um breve retrospecto histórico com o objetivo de compreender a relação entre os altos índices de crianças refugiadas em situação precária com a universalização dos direitos humanos, tendo como enfoque a estrutura governamental brasileira para lidar com as implicações educacionais dessa situação.

No quesito metodológico, se apresenta como uma pesquisa bibliográfica com fundamentação na pesquisa documental da área, como legislação, declarações internacionais, dados da ONU, Organização Internacional para as Migrações - OIM e Alto Comissariado das Nações Unidas - ACNUR, análise bibliográfica e decisões judiciais internacionais relevantes. $O$ referencial teórico para fins conceituais e para construção do questionamento da pesquisa parte da tese de Isabelle Dias Carneiro de Santos sobre "A proteção das crianças e adolescentes refugiados no Brasil: A necessidade de políticas públicas de integração". Para fins deste trabalho será adotado o critério de crianças como indivíduos com menos de 18 anos conforme a Convenção sobre os Direitos das Crianças de 1989.

Por fim, espera-se que sejam encontrados os porquês da situação precária das crianças diante da realidade brasileira, bem como as correlações com a seara educacional. Dentre as hipóteses preliminares do que seria o causador da problemática 
se encontram o contexto legislativo e social do país, bem como o surgimento do conceito de refúgio e sua interpretação jurídica normativa. Assim, busca-se entender a aplicabilidade dos regimes internacionais de Direitos Humanos para crianças refugiadas para que possam ser tomadas medidas concretas quanto à inclusão educacional.

\section{CONCEITOS DE REFÚGIO E CRIANÇA NO BRASIL}

Antes de adentrar diretamente no conceito e na aplicação do instituto do refúgio, é necessário contextualizar o conceito de criança e adolescente, os direitos destes e sua relevância no momento jurídico atual. A configuração atual desses conceitos só foi possível com o surgimento da New York Society for the Prevention of Cruelty to Children (Sociedade de Prevenção da Crueldade contra Crianças de Nova York), em 1874, após o notável caso de Mary Ellen. A menina de apenas nove anos era constantemente submetida a severos maus tratos por seus responsáveis, e ao ter seu caso denunciado foi preciso se valer de uma analogia com o direito dos animais, pois as crianças não eram tuteladas juridicamente àquele tempo (WATKINS, 1990).

Desde o relatado episódio, construiu-se um leque de dispositivos internacionais para a defesa dessa parte da sociedade. Tem-se como a mais famosa e de maior implicância na redação do Estatuto da Criança e do Adolescente, a Convenção sobre os Direitos da Criança, Resolução 44/25 da Assembleia Geral da ONU de 20 de novembro de 1989. O Brasil, por sua vez, já possuía normas legais para pessoas abaixo da maioridade civil desde o Decreto 17.943-A de 1927, posteriormente substituído pela Lei 6.697/79, também chamada de Código de Menores. No entanto, ambos tinham caráter mais disciplinar e tutelar do que educativo propriamente dito (TRICANO, 2017).

Após o fim do período de ditadura militar e sob os novos paradigmas contestados pela ONU é que se ergueu em 1990 a Lei 8.069, chamada de Estatuto da Criança e do Adolescente - ECA. Esse trouxe uma nova função social para a família e o novo entendimento sobre a criança e o adolescente, em conjunto à Constituição Cidadã de 1988 e o Código Civil de 2002. A partir de então passaram a ser vistos como um indivíduo em desenvolvimento por sua imaturidade biopsíquico-social, que necessita de proteção especial (TAVARES, 2018).

Nesse diapasão, é importante frisar que o conceito de criança e adolescente adotado pelo nosso ordenamento jurídico, disposto no artigo $2^{\circ}$ da Lei 8.069 , partiu dessa construção social. Portanto, é de suma importância entender que entre essas faixas etárias há grande instabilidade na construção psicológica do ser humano, nesse sentido é que se faz eminentemente necessária uma abordagem diversificada do indivíduo perante a justiça e políticas públicas, isto é do que se trata o presente estudo (TRICANO, 2017).

Como é possível observar a partir de um comparativo com a Convenção sobre Direitos das Crianças e dos Adolescentes da ONU, a denominação e os direitos direcionados aos indivíduos com dezoito anos em suas mais diversas situações é bastante similar à nacional. O contraponto é que no direito interno encontra-se a divisão entre crianças, para pessoas com menos de doze anos, e adolescentes, quando se trata de pessoa entre doze e dezoito anos. Nesse sentido, para fins metodológicos desta 
FLORENCIO, G. de C.

pesquisa, adotou-se o conceito de criança adotado pela Convenção Internacional (UNICEF, 1989).

Neste intricado conceito é que resta configurado o direito à educação, primeiramente elencado na Constituição Federal de 1988:

Art. 227. É dever da família, da sociedade e do Estado assegurar à criança, ao adolescente e ao jovem, com absoluta prioridade, o direito à vida, à saúde, à alimentação, à educação, ao lazer, à profissionalização, à cultura, à dignidade, ao respeito, à liberdade e à convivência familiar e comunitária, além de colocá-los a salvo de toda forma de negligência, discriminação, exploração, violência, crueldade e opressão (BRASIL, 1988).

A educação é de prestação obrigatória e gratuita para todas as crianças igualmente. Também é nesse mesmo sentido que o Estatuto da Criança e do Adolescente se posiciona:

Art. $4^{\circ}$ É dever da família, da comunidade, da sociedade em geral e do poder público assegurar, com absoluta prioridade, a efetivação dos direitos referentes à vida, à saúde, à alimentação, à educação, ao esporte, ao lazer, à profissionalização, à cultura, à dignidade, ao respeito, à liberdade e à convivência familiar e comunitária (ECA, 1989).

O Estatuto da Criança e do Adolescente assegura em seu texto o direito à primazia e proteção dessas pessoas, visando a seu pleno desenvolvimento.

Ainda no que diz respeito ao conceito de refúgio, é mister ressaltar que após a Segunda Guerra Mundial a situação dos imigrantes no mundo era de extrema precariedade, o que fez com que os países se reunissem com apoio da Organização das Nações Unidas para a realização da Convenção de Genebra em 1951, de modo a reconhecer como refugiados as vítimas de violação aos direitos básicos, contudo é importante dizer que a norma se restringia apenas a pessoas que fugiram até o referido ano (PIOVESAN, 2016).

Com o passar do tempo, os refugiados se espalharam pelo mundo, o que fez com que fosse necessária a realização de um novo acordo, chamado Protocolo de 1967, estendendo o direito de forma atemporal. No âmbito da América Latina, anos depois, foi assinada a Declaração de Cartagena de 1984, que determinou o conceito de forma abrangente para quem sofre qualquer tipo de violação maciça aos direitos humanos (ACNUR, 1984). Diante da situação política vivida no Brasil, ele foi signatário da Declaração naquele tempo, a qual foi incorporada ao ordenamento jurídico interno a partir da Constituição Federal de 1988 (GONÇALVES; SALLES, 2016).

Finalmente, no ano de 1997, o Brasil internalizou os tratados, tendo criado o Estatuto dos Refugiados para abranger a temática (Lei 9.474). Nesse documento, ficou expressa a condição dos refugiados conforme documentos supracitados, sendo assegurado ainda o direito à documentação legal e à reunião familiar. Nesse mesmo dispositivo legal foi criado o Conselho Nacional para os Refugiados - CONARE, que passou a trabalhar em conjunto com a Polícia Federal, responsável pelo controle de fronteiras na recepção e direcionamento dessas pessoas (BRASIL, 1997). 
Ademais, sobre a recepção e validade dos tratados internacionais no Brasil, deve-se relembrar que desde a Emenda Constitucional 45 de 2004, o país tem admitido a jurisdição do Tribunal Penal Internacional, bem como aceito a recepção dos tratados internacionais com status de emenda da constituição mediante aprovação por quórum qualificado, ações que proporcionam mais influência interna desses acordos internacionais (PORTELA, 2018, p. 1107-1109).

\section{POLÍTICAS PÚBLICAS}

Partindo dos conceitos apresentados, pode-se afirmar que para asseguração do direito das crianças em situação de refúgio é essencial a tomada de ações práticas de natureza governamental, nesse sentido é que agem as chamadas políticas públicas. Elas são criadas de modo a propiciar o acesso aos direitos básicos como saúde, lazer, educação e cultura, garantido a qualquer pessoa consoante art. $6^{\circ}$ da Constituição Federal. A terminologia "políticas públicas" não possui um significado consolidado, contudo a doutrina traz ideias de como programas governamentais podem lidar com questões sociais relevantes a partir de uma atuação política (SANTOS, 2018). Ainda assim, Maria Coeli Simões Pires traz a relevante significação de que políticas públicas são “[...] respostas do Estado a questões ou de interesse da sociedade, as quais se desenvolvem em três momentos: o da concepção, o da orçamentação e o da implementação [...]". Por meio dessa interpretação verifica-se que as políticas públicas tratam na verdade de uma forma de atuação ativa na sociedade pelo Estado (PIRES, 2002).

Nesse sentido, o Brasil criou um órgão de controle denominado Comitê Nacional para os Refugiados - CONARE, de modo a promover a melhor recepção e reconhecimento da condição desses refugiados. Entretanto, a legislação brasileira se encontra em defasagem em relação à recepção das crianças. Por exemplo, em 2013, o ACNUR, em parceria com a UNICEF, assinou um memorando que recomendava a concessão de documentos às crianças, podendo estar acompanhadas ou não, para propiciar o uso dos benefícios sociais (SANTOS, 2018). Ademais, uma grande problemática envolvendo a solicitação dessas crianças é o fato de muitas delas estarem desacompanhadas, razão pela qual não conseguem fazer o pedido de documentação sozinhas na Polícia Federal, sendo necessário buscarem a Defensoria Pública para abertura do processo de tutela e direcionamento ao abrigo (MARTUSCELLI, 2017).

No aspecto educacional é importante frisar que a partir de um estudo da Lei de Diretrizes da Educação - Lei n. 9394, não há normatização em patamar legal quanto aos estudantes imigrantes, nem de sua recepção ou revalidação de estudos até o Ensino Médio. Para sanar a lacuna legal, o Ministério da Educação aprovou uma Resolução que delimita a forma de revalidação de estudos no estrangeiro por meio de correspondência de carga horária e currículo, nos termos da Resolução do Conselho Federal de Educação no 05/79, em fase da igualdade entre brasileiros e estrangeiros (BRASIL, 2019). Posteriormente, o Ministério da Educação aprovou uma nova Resolução publicada em novembro de 2020 especificando as medidas de inclusão e documentação, como se pode ver:

Inter-Ação, Goiânia, v.46, n.2, p. 592-606, maio/ago. 2021. Disponível em: <http://dx.doi.org/10.5216/ia.v46i2.67348>. 
FLORENCIO, G. de C.

\begin{abstract}
Art. $6^{\circ}$ As escolas devem organizar procedimentos para 0 acolhimento dos estudantes migrantes, com base nas seguintes diretrizes:

I - não discriminação;

II - prevenção ao bullying, racismo e xenofobia;

III - não segregação entre alunos brasileiros e não-brasileiros, mediante a formação de classes comuns;

IV - capacitação de professores e funcionários sobre práticas de inclusão de alunos não-brasileiros;

V - prática de atividades que valorizem a cultura dos alunos nãobrasileiros; e

$\mathrm{VI}$ - oferta de ensino de português como língua de acolhimento, visando $a$ inserção social àqueles que detiverem pouco ou nenhum conhecimento da língua portuguesa (BRASIL, 2020).
\end{abstract}

Nesse sentido, é possível dizer que o Estado Brasileiro estaria descumprindo até 2020 com o pactuado por meio da Convenção sobre os Direitos da Criança. Isto é, apesar de o Brasil ter admitido a cooperação por meio da educação, na prática deixava de suprir as necessidades das crianças refugiadas, portanto, encontrava-se em descumprimento do pacto internacional. Seu descumprimento violava diretamente os precedentes básicos e os direitos humanos desses indivíduos, e ainda encontra desafios em transformar o direito formal em material tendo em vista a necessidade de aplicação dessa resolução e inexistência de normas em patamar legal.

Nesse sentido, é importante ressaltar que esses indivíduos podem ser o meio principal, em sua família, de inserção na comunidade e aprendizado da língua por terem contato com a educação formal, o que não pode ser ignorado de um aspecto social, razão pela qual essa adequação precisa abordar uma integração social, que consiste na inclusão local dos indivíduos (SANTOS, 2018). No Brasil, o atendimento psicológico dessas crianças tem sido feito em alguns estados por meio do sistema público nos órgãos dos Centros de Atenção Psicossocial - CAPS e no sistema privado por meio de parcerias como, por exemplo, a atuação da Cáritas, ente da Igreja Católica que atua no atendimento e acolhimento de refugiados, em uma parceria com o Hospital das Clínicas em São Paulo, sendo tratado pela psicologia os resquícios da perseguição forçada e xenofobia quando da integração social (MARTUSCELLI, 2017).

Pode-se ver o quão recente é a problemática, suas lacunas legais e a ausência de políticas públicas. Nesse diapasão, Charles Gomes, coordenador do Centro de Proteção a Refugiados e Imigrantes - Cepri, da Fundação Casa de Rui Barbosa, relata: "Dificuldades que eles [refugiados] têm em termos de revalidação do diploma, de cursar escola pública quando estão em situação de refúgio no país, dificuldade de acessar, na verdade, os seus direitos, desinformação em relação à possibilidade de naturalização" (FRAGA, 2019).

Em reportagem da revista Gazeta do Povo, a diretora da ONG I Know My Rights IKMR afirma que muitas vezes há uma complicação para matrícula dessas crianças refugiadas em razão do documento da política federal não ser o exigido pela Lei de Diretrizes e Bases da Educação Nacional - LDB, bem como pela ausência de histórico escolar. Não bastando as dificuldades burocráticas para realização da matrícula, existem as sociais, pela integração cultural e familiar, em razão do número imenso de crianças desacompanhadas que buscam refúgio (FADDUL; MUNIZ, 2018). 
Ainda sobre dados, segundo o Comitê Nacional para os Refugiados - CONARE, o Brasil registrou 22.627 refugiados reconhecidos, de 53 nacionalidades distintas entre os anos de 2018 e 2019 . O número de solicitações de refúgio quase triplicou de 2015 para 2019. A maior fatia de solicitações provém das regiões de guerra e instabilidade política, como África, Ásia (inclusive a Síria, de onde vem a maioria), América do Sul (venezuelanos) e o Caribe. Curiosamente, segundo dados do ACNUR, nos referidos anos apenas $2.33 \%$ das solicitações eram de menores de 18 anos, o que aumenta se for considerado o percentual de crianças que tiveram o pedido deferido, que se converte no percentual de mais de $7 \%$ do total (CONARE, 2020).

Apesar de a quantia não parecer tão expressiva se comparado aos números de adultos refugiados, o Brasil ainda se encontra entre os 10 países que mais recebem crianças em situação de refúgio (ONU, 2016). A situação nas Américas se agravou, o que tem feito com que os países busquem medidas e acordos de proteção, como o acordo de Cartagena +30 ocorrido em 2014, documento em que foram ressaltadas a prioridade e preocupação com esse grupo vulnerável (SANTOS, 2018).

Em comparação com o aspecto global, o Brasil não demonstra uma situação tão crítica, contudo é preocupante. O Alto Comissariado das Nações Unidas para Refugiados - ACNUR declarou pelo relatório "Stepping Up" que de 2014 até 2018 mais de 50\% dos refugiados no mundo eram menores de 18 anos de idade e que 3.7 milhões destes, em idade escolar, estavam fora da escola (GRANDI, 2019).

Em termos práticos, as dificuldades de recepção vão desde a questão da língua até a falta de informação, esta em uma menor intensidade segundo dados do IPEA de 2015, contudo o que realmente faz com que a situação se agrave é a falta de interesse em promover o acolhimento. Quando o governo e a população enxergam os refugiados como causadores das problemáticas sociais, mesmo ante a existência de leis rígidas ou tratados internacionais, a prática de internalização e efetivação de direitos se torna complexa (SILVA; FERNANDES, 2018).

\section{CONTEXTO DE PANDEMIA}

Em março de 2020 foi declarada pandemia pela ONU em razão da epidemia generalizada da doença COVID-19, que se espalhou por 114 países, popularmente conhecida como "Coronavírus". O vírus foi identificado entre dezembro de 2019 e janeiro de 2020 na cidade de Wuhan na China, primeiro epicentro doença, de origem desconhecida por se tratar de uma mutação do vírus COVID. A preocupação com a doença advém do seu alto grau de contágio e taxa de letalidade considerável entre grupos vulneráveis e portadores de comorbidades (CASCELLA et al., 2020).

Desde a declaração, o ACNUR vem reforçando a comunicação com as comunidades de refugiados em todo país. Dentre as maiores preocupações dos órgãos internacionais está a comunicação e informação adequada para que sejam tomadas as medidas de higiene necessárias à prevenção da doença, principalmente em relação às comunidades que se encontram em abrigos e assentamentos por causa da possível insalubridade de sua situação (GRANDI, 2020). 
No Brasil, a situação agrava-se ainda diante da dificuldade de recepção dos refugiados em razão de as fronteiras estarem sob controle e o país se encontrar em uma crise econômica, com o judiciário e o executivo saturados das demandas da pandemia. Nesse sentido, no dia 20 de junho de 2020, a Comissão Interamericana de Direitos Humanos, em homenagem ao Dia Mundial do Refúgio apresentou um relato de suas análises sobre o fluxo de refugiados no meio da pandemia, estimando que haveria mais de 18 milhões de pessoas deslocadas pelo mundo, dentre esses mais de 5 milhões de venezuelanos. Apesar da aparente celeridade do CONARE em decidir um dos casos de forma massiva, os prognósticos indicam que os julgamentos favoráveis abarcam apenas uma pequena fatia dos deslocados. Além disso, a maior preocupação do ente internacional reside no fato de as fronteiras estarem fechadas ou, no mínimo, mais restritas, bem como na suspensão de prazos no judiciário. Nesse sentido, apresentam-se as recomendações para garantir os direitos básicos e prevenir a xenofobia.

Em razão das dificuldades sanitárias, o grupo de refugiados se torna mais do que nunca vítima social e materialmente. No aspecto social, estudos têm apontado o aumento da xenofobia, bem como o olhar de culpabilização dos estrangeiros pelo alastramento da doença. Por outro diapasão, esse grupo também se vê restrito materialmente na questão de acesso aos bens de higiene necessários e à água para sua saúde, especialmente as crianças nessa situação (CIDH, 2020).

Nesse ponto a Corte recomenda, por meio da Resolução 01/2020 sobre a COVID-19, que sejam acelerados os julgamentos, evitadas as expulsões, ainda mais quando a pessoa puder retornar a um país onde não há os recursos mínimos de saúde, facilitar o retorno dessas pessoas ao país natal se assim quiserem, bem como a promoção de estratégias de combate à xenofobia. Ademais, especificamente quanto às crianças, a Resolução recomenda a implantação de medidas educacionais a distância, apoio familiar e essencialmente o combate à violência contra crianças (CIDH, 2020).

A dificuldade do Brasil em seguir as recomendações consiste em um problema de implementação de políticas públicas que resta sintetizado no embate entre o Princípio do Mínimo Existencial versus o Princípio da Reserva do Possível. Quando se trata de princípios que não podem anular-se uns aos outros, estes devem ser aplicados de forma compartimentada por meio do equilíbrio juridicamente denominado ponderação, ou seja, a aplicação no caso concreto em que um princípio não anule o outro, método desenvolvido por Robert Alexy (ALEXY, 2006). O conflito surge pela própria dicotomia entre os princípios, considerando que nada é absoluto na concretude do judiciário, uma vez que nem tudo pode ser quantificado.

Por fim, no que tange aos direitos sociais mínimos dessas crianças refugiadas, com o decorrer da pandemia sua proteção se tornou cada vez de mais difícil acesso e o Mínimo Existencial uma meta distante. Segundo o relatório do ACNUR, "Coming Together for Refugee Education", publicado em setembro de 2020, o fechamento das escolas, reflexos na economia e comércio impactaram diretamente a vida dessas crianças. Por todo o mundo, as pessoas perderam o emprego, passando a depender de auxílios governamentais e acesso à internet, instrumentos que os refugiados muitas vezes sem documentação ou estrutura financeira não possuem, muitos ainda não tem acesso à água limpa, ao saneamento, à moradia, ao transporte e ao emprego formal.

No quesito da desigualdade, há que se apontar uma diferença entre os vulneráveis: as meninas ainda são as mais atingidas no acesso escolar. O relatório ainda 
aponta que elas frequentam menos a escola secundária do que os meninos. Nesse sentido, o Instituto Malala estima que $50 \%$ das meninas refugiadas não vão conseguir retornar à escola caso reabram no ano de 2020. Em alguns países, as mulheres ainda são proibidas e até perseguidas caso queiram estudar.

As bases metodológicas dessas estatísticas foram feitas com referência no ano de 2019 em uma coleta de dados por meio administrativo e por entrevista de 10.539 .446 refugiados de doze países: Chade, Etiópia, Iraque, Jordânia, Quênia, Líbano, Paquistão, Ruanda, Sudão do Sul, Tanzânia, Turquia, Uganda, o que apresenta quase metade dos refugiados sob o mandato do ACNUR. Visando a solucionar essa problemática, a ONU instituiu o dia 09 de setembro como Dia Internacional de Proteção contra Ataques à Educação, para que a Assembleia Geral possa impor medidas contra usos de controles militares e ataques escolares (GRANDI, 2020).

Ainda no que diz respeito à educação, a Cátedra Sérgio Vieira de Mello - CSVM trouxe mais reflexões o sobre as consequências da COVID-19. A CSVM foi implementada em 2003 pelo ACNUR como meio de cooperação com as Universidades no Brasil e o CONARE, visando ao desenvolvimento da educação e pesquisa acadêmica voltada para os refugiados. O nome da Cátedra é uma homenagem ao funcionário do ACNUR, Sérgio Vieira de Mello, que dedicou toda sua vida profissional à questão do refúgio, morto no Iraque em 2004. O acordo de cooperação parte de um termo com objetivos práticos distribuídos em três pontos: educação, pesquisa e extensão.

As ações da cooperação têm como objetivo final a aplicação prática das pesquisas em projetos comunitários e iniciativas para acesso e incentivo de refugiados à educação. Nesse sentido, por sua vez, o relatório de 2020 apontou que, além da dificuldade propriamente na seara educacional, há a complicação para os pais de crianças que precisam sair para trabalhar ou buscar emprego, o que ou os limita economicamente ou expõe essa criança ao risco de ficar sozinha em casa. Em contrapartida, sobre a educação dessas crianças, o relatório afirmou haverem universidades parceiras realizando cursos de formação para professores e programas de extensão para acompanhamento do desenvolvimento escolar. Um exemplo é a Universidade Estadual do Rio de Janeiro - UERJ, que realizou um programa de extensão de formação continuada para o trabalho com refugiados, migrantes, indígenas e portadores de necessidades especiais (EGAS, 2020).

\section{JURISPRUDÊNCIA}

Nesse patamar, visando à seguridade educacional dos direitos fundamentais dos refugiados, apresentar-se-á o debate jurídico sobre o direito de registros pelas crianças refugiadas levado ao Superior Tribunal de Justiça. O caso discutia se era obrigatória a apresentação de Certidão de Nascimento de criança refugiada no momento da matrícula escolar. Considerando a omissão legal e a melhor interpretação para defesa dos direitos básicos desses indivíduos, o Registro Nacional do Estrangeiro foi equiparado com a certidão (STJ, 2017).

O caso citado acima representa um dos vários ocorridos entre crianças que ingressam o território brasileiro sem nenhuma documentação. O entrave era que a 
legislação interna exige a apresentação de documento de identificação, bem como certidão de nascimento, para uso das garantias constitucionais como saúde e educação, o que por vezes é inviável para pessoas em situação de refúgio. Após essa decisão do Tribunal, passou-se a equiparar para fins legais o Registro Nacional de Estrangeiro à Certidão de Nascimento, ante a ausência de abordagem legislativa do tema, situação que foi apenas mediada pela resolução publicada em 2020.

Ademais, é essencial destacar que a presente decisão encontrou respaldo na esfera internacional, sendo assegurada a emissão de documento para refugiados, de modo a usufruírem de seus direitos básicos. Assim dispõe o art. 27 da Convenção de Genebra de 1951: “Os Estados Contratantes passarão documentos de identidade a todos os refugiados que se encontrem nos seus territórios e não possuam documento de viagem válido" (ONU, 1951). Ainda sobre a referida temática, direito à documentação, bem como o acesso aos direitos humanos para pessoas indocumentadas, existem decisões jurisprudenciais da Corte Interamericana de Direitos Humanos no mesmo sentido, o Parecer Consultivo 18/03 por solicitação do México. Nesse documento ressaltou-se que a aplicação dos princípios da igualdade e não discriminação são obrigatórios e de caráter erga omnes (BRASIL, 2014).

Por fim, no que diz respeito aos julgados e à atuação administrativa do Brasil, passa-se para uma análise à luz dos órgãos regionais das Américas. O relatório "Política de Migração e Refúgio do Brasil Consolidada" criado pela Organização Internacional para as Migrações - OIM, o ACNUR e o Programa das Nações Unidas para o Desenvolvimento - PNUD apresentam uma série de dados e conclusões sobre a atuação do Brasil na esfera regional. Para tanto, foi afirmado que no contexto do Brasil na América Latina, o país tem se destacado no que diz respeito ao Plano de Ação Brasil $P A B$, que busca a criação e um campo de refúgio visando a integrar essas pessoas, a criação de fronteiras solidárias por meio de programas de monitoramento e atendimento de refúgio, como a Operação Acolhida, além de soluções permanentes.

Ademais, concluiu-se que a problemática de uma possível lentidão e falha no julgamento das solicitações administrativas pelo CONARE não advém de uma falha normativa, pelo contrário, sua maior dificuldade está em sua estrutura administrativa. Ou seja, é necessária uma melhor gestão do órgão e o investimento para a ampliação do atendimento. Ainda afirmou-se que: "Do ponto de vista da regulamentação, a única proposta levantada pelos interlocutores ouvidos no projeto foi a desburocratização dos pedidos, com simplificação documental". A redução dessa burocracia já foi vista no atendimento de crianças acompanhadas na Operação Acolhida (OIM, 2017).

No sentido específico desta pesquisa, cabe frisar dentre os pareceres da Corte Interamericana dos Direitos Humanos o julgado em 1997, que emitiu parecer para seus Estados-membros para fins de assegurar a proteção integral das crianças:

COMISSÃO INTERAMERICANA DE DIREITOS HUMANOS APLICAÇÃO DAS MEDIDAS ESPECIAIS DE PROTEÇÃO DESTINADAS ÀS CRIANÇAS. INTERPRETAÇÃO DOS ARTIGOS 8, 19 E 25 DA CADH. A Corte emitiu parecer no sentido de que "as obrigações de proteção dos direitos das crianças devem ser consideradas como obrigações erga omnes. Do mesmo modo, os Estados devem prezar pela preservação dos direitos materiais e processuais das crianças em todas e quaisquer circunstâncias, não se admitindo a discricionariedade do Estado na 
proteção dos menores de 18 anos", conforme doutrina da proteção integral (PAIVA, 2017).

O julgado, ao determinar a obrigação do Estado e de todos os indivíduos de proteger as crianças, criou uma orientação para os países recepcionarem esses indivíduos da melhor forma, bem como abriu precedente para novos pareceres e orientações mais protetivas (PAIVA, 2017).

No sentido de proteção dessas crianças e adolescentes, deve-se ressaltar que segundo a psicologia jurídica esses são prejudicados em seu íntimo quando sem acesso à educação, à inclusão social, ao afeto e aos vínculos familiares. A institucionalização prolongada dessas pessoas também aumenta consideravelmente a sensação de abandono e rejeição, uma vez que não compreende as questões jurídicas e burocráticas. Portanto, esses indivíduos que são o futuro do país precisam de intervenções o mais rápido possível (WEBER, 1995).

No que tange à situação da COVID-19, a Corte orientou os países signatários a integrarem os refugiados e oferecem suporte às crianças, por meio da Resolução 01/2020, conforme abordado no capítulo anterior desta pesquisa. No final do mês de abril do ano de 2020, a Corte reiterou a Resolução pelo Comunicado à empresa: "A CIDH alerta para as consequências da pandemia do COVID-19 em crianças e adolescentes"; solicitando atenção às crianças expostas à violência doméstica e desigualdade de gênero. Sobre o Brasil, o elogiou pela Recomendação do Ministério da Mulher, Família e Direitos Humanos do Brasil no sentido de que os municípios não deixassem o funcionamento dos Conselhos Tutelares suspensos (CIDH, 2020).

\section{CONSIDERAÇÕES FINAIS}

A partir da presente pesquisa, observou-se que no sentido da aplicação dos direitos básicos voltados para educação e inclusão de crianças refugiadas, o Brasil ainda é pouco robusto em suas ações políticas, dependendo de órgãos internacionais ou mesmo de ONGs, o que demonstra precariedade em sua atuação e leva ao questionamento sobre o verdadeiro acesso à justiça. Apesar disso, verificou-se que o país tem caminhado em um sentido de regulamentação das questões envolvendo a educação dessas pessoas em situação de refúgio, ainda que por meio de resoluções. Em contrapartida, no sentido material as normas encontram entraves no acolhimento desses indivíduos por causa da xenofobia, da dificuldade de comunicação pela língua e da empatia social.

No que tange ao aspecto temporal, é necessário ressaltar que a pandemia da COVID-19 atingiu principalmente as pessoas vulneráveis, como os refugiados, por prejudicar diretamente a saúde e o acesso à educação. O Brasil foi um dos grandes atingidos pela pandemia, razão pela qual a Corte Interamericana de Direitos Humanos publicou uma Resolução que orientava as medidas a serem tomadas para refugiados no contexto, mesmo diante do fechamento de fronteiras e escassez de recursos. Ressaltase, ainda, a imprescindibilidade de assegurar a esses indivíduos o mínimo existencial, ou seja, seus direitos básicos. Segundo os dados das Cátedras Sérgio Vieira de Mello e 
Instituto Malala, a educação foi uma das áreas mais afetadas, principalmente pela falta de recursos, ressalvada a maior evasão escolar de meninas pelo mundo.

Estudou-se também a aplicação material na seara jurídica e administrativa, nas quais manifesta-se uma tendência a seguir decisões da Corte Interamericana de Direitos Humanos e interpretações pelo melhor interesse das crianças. Ademais, a maior dificuldade apontada pela OIM nesse sentido é de que ainda é necessária uma desburocratização do procedimento documental para ingresso desses indivíduos.

Por fim, observa-se que a criança refugiada ainda se depara com uma série de dificuldades materiais e mesmo formais pela ausência de legislação e atuação de políticas estatais. Esses indivíduos passam a depender da atuação de ONGS e Órgãos Sociais, o que vai de encontro com a necessidade de seguridade social e acesso aos direitos básicos. A ausência de dispositivo legal no mesmo patamar do ECA denota a falta de segurança jurídica dessas crianças.

Artigo recebido em: 13/01/2021

Aprovado para publicação em: 28/05/2021

\section{CHILDREN HUMAN RIGHTS INTO BRAZIL IN XXI CENTURY: EDUCATIONAL QUESTIONS}

ABSTRACT: This research deals with the application of International Regimes in the Human Rights of Refugee Children in Brazil in the 21st century and its implications in the educational field. Then, the research aims to understand the consolidation and internalization of basic educational rights and the social integration of children. Still, it shows itself as a bibliography study based on documentary research in the area, whether by legislation, doctrines and treaties. Finally, it was concluded that the country has legally applied international agreements in a formal aspect, however, it is poorly developed in terms of public policies, unified legislation and effective protection for these individuals.

KEYWORDS: Refugee. Children. Human Rights. Education.

\section{LOS DERECHOS HUMANOS DE LOS NIÑOS REFUGIADOS EN BRASIL EM EL SIGLO XXI: RELACIONES} EDUCATIVAS

RESUMEN: Esta investigación aborda la aplicación de los regímenes internacionales en los derechos humanos de los niños refugiados en Brasil en el siglo XXI y sus implicaciones en el campo educativo. En este sentido, el objetivo de la investigación es comprender la consolidación e internalización de los derechos educativos básicos apuntando a la integración de estos niños. Aun así, se presenta como una pesquisa bibliográfica basada en la investigación documental en el área, ya sea por legislación, doctrinas y tratados. Finalmente, se concluyó que el país ha aplicado legalmente los acuerdos internacionales en un aspecto formal, sin embargo, está poco desarrollado en cuanto a políticas públicas, legislación unificada y protección efectiva para estos individuos. 
PALABRAS CLAVE: Refugiados. Niños. Derechos Humanos. Educación.

\section{REFERÊNCIAS}

ACNUR. Declaração De Cartagena, 1984. Colóquio sobre Proteção Internacional dos Refugiados na América Central, México e Panamá: Problemas Jurídicos e Humanitários. 1984.

ALEXY, R. Teoria dos direitos fundamentais. Trad. Virgílio Afonso da Silva. 5. ed. São Paulo: Malheiros, 2006, p. 85-179.

BRASIL. Resolução do Conselho Federal de Educação nº 05/79. Ministério da Educação, Brasília, $1979 . \quad$ Disponível em: portal.mec.gov.br/cne/arquivos/pdf/rcfe05_79.pdf. Acesso em: 11 ago. 2020.

BRASIL. Estatuto da Criança e do Adolescente, 1990.

BRASIL. Constituição Federativa do Brasil, 1988.

BRASIL. Lei n० 9.474, de 1997. Define mecanismos para a implementação do Estatuto dos Refugiados de 1951, e determina outras providências. Brasília-DF, 1997.

BRASIL. Jurisprudência da Corte Interamericana de Direitos Humanos. Secretaria Nacional de Justiça, Comissão de Anistia, Corte Interamericana de Direitos Humanos. Tradução da Corte Interamericana de Direitos Humanos. Brasília: Ministério da Justiça, 2014, 7 v.

BRASIL. Resolução do Conselho Federal de Educação n 01/2020. Ministério da Educação, Brasília, 2020, ed. 218, seção 1, p. 61.

CASCELLA, M.; RAJNIK, M.; ALLEM, A.; CUOMO, A.; DULEBOHN, S. C.; NAPOLI, R. D. Features, Evaluation, and Treatment of Coronavirus (COVID-19). Stat Pearls Publishing, Treasure Island (Florida), jan. 2021. Disponível em: https://www.ncbi.nlm.nih.gov/books/NBK554776/. Acesso em: 11 ago. 2020.

CIDH. A CIDH alerta para as consequências da pandemia do COVID-19 em crianças e adolescentes. Washington, D.C.: Organização dos Estados Americanos, n. 090, 2020. Disponível em:/www.oas.org/pt/cidh/prensa/notas/2020/090.asp. Acesso em: 10 set. 2020.

CONARE. Decisões Plenária Conare. Disponível em: app.powerbi.com/view?r=eyJrljoiNTQ4MTU0NGItYzNkMi00M2MwLWFhZWMtMDBiM2I1 
FLORENCIO, G. de C.

NWVjMTY5liwidCI6ImU1YzM3OTgxLTY2NjQtNDEzNC04YTBjLTY1NDNkMmFmODBiZSIsI mMiOjh9. Brasília: Ministério da Justiça e Segurança Pública. Acesso em: 10 maio 2020.

EGAS, J. Relatório Anual Cátedra Sérgio Vieira de Mello de 2020. Brasília: ACNUR, 2020, Disponível em: https://www.acnur.org/portugues/wpcontent/uploads/2020/09/Relat\%C3\%B3rio-Anual-CSVM-2020.pdf. Acesso em: 10 set. 2020.

EGAS, J. 15 anos de cátedra Sérgio Vieira de Mello no Brasil: universidades e pessoas refugiadas. Organizado por José Blanes Sala et al. São Bernardo do Campo, São Paulo: Universidade Federal do ABC, 2020.

FADDUL, J.; MUNIZ, A. Os desafios para inserir refugiados nas escolas brasileiras. Curitiba, Paraná: Gazeta do Povo, 2018. Disponível em: www.gazetadopovo.com.br/educacao/os-desafios-para-inserir-refugiados-nas-escolasbrasileiras-822xhyanr24jnb569n7phgkn1/. Acesso em: 23 abr. 2020.

FERNANDES, D.; SILVA, F. R.; SPRANDEL, M. A. et al. Caderno de Debates Refúgio, Migrações e Cidadania. Brasília: Instituto Migrações e Direitos Humanos, v. 13, n. 13, 2018. p. 37-60, 83-102.

FRAGA, E. Relatório aponta que refugiados necessitam de mais políticas públicas. Brasília: Agência Brasil, 2019. Disponível em: agenciabrasil.ebc.com.br/direitoshumanos/noticia/2019-09/relatorio-aponta-que-refugiados-necessitam-de-maispoliticas. Acesso em: 15 abri. 2020.

GRANDI, F. Relatório STEPPING UP. Genebra, Suíça: ACNUR, 2019. Disponível em: www.unhcr.org/steppingup/wp-content/uploads/sites/76/2019/09/Education-Report2019-Final-web-9.pdf. Acesso em: 16 mar. 2020.

GRANDI, F. Coming Together for Refugee Education. Genebra, Suíça: ACNUR, 2020. Disponível em: www.unhcr.org/5f4f9a2b4. Acesso em: 9 set. 2020.

GONÇALVES, F. C. N. I.; SALES, Denise M. N. N L. A atuação do estado brasileiro na proteção dos refugiados: a distância entre a legislação e a garantia dos direitos humanos. Revista Brasileira de Políticas Públicas e Internacionais, Paraíba. v. 1, n. 2, set./dez. 2016, p. 111-132.

MARTUSCELLI, P. N. et al. Direitos humanos e vulnerabilidade em políticas públicas [e-book]. Santos- SP: Editora Universitária Leopoldianum, 2017.

OIM. Política de refúgio do Brasil consolidada. Marcelo Torelly, (coord.); Aline Khoury, Luís Renato Vedovato, Veronica Korber Gonçalves. Brasília: Organização Internacional para as Migrações, Agência das Nações Unidas Para as Migrações, 2017. 
ONU. Declaração Universal dos Direitos Humanos. Assembleia Geral das Nações Unidas, Genebra:1948.

ONU. Convenção de Genebra de 1951 relativa ao Estatuto dos Refugiados. Genebra: 1951.

ONU. Declaração de Nova lorque. Nova lorque: Assembleia Geral da ONU, 2016. Disponível em: www.un.org/pga/70/wp-content/uploads/sites/10/2015/08/HLM-onaddressing-large-movements-of-refugees-and-migrants-Draft-Declaration-5-August2016.pdf. Acesso em: 5 ago. 2020.

PAIVA, C.; HEEMANN, T. A. Jurisprudência Internacional de Direitos Humanos. 2. ed. Belo Horizonte: CEl, 2017.

PIOVESAN, F. Direitos Humanos e o Direito Constitucional Internacional. 16. ed. São Paulo - SP: Editora Saraiva, 2016, p. 73-416.

PIRES, M. C. S. Concepção, Financiamento e Execução de Políticas Públicas no Estado Democrático de Direito. Revista do Tribunal de Contas de Minas Gerais, Belo Horizonte, abr.-jun., 2002.

PORTELA, P. H. G. Direito internacional público e privado: incluindo noções de direitos humanos e de direito comunitário. 12. ed. Salvador: JusPODIVM, 2018.

SANTOS, I. D. C.. A proteção das crianças e adolescentes refugiados no Brasil: A necessidade de políticas públicas de integração. Tese - Universidade Presebiteriana Makenzie. São Paulo - SP, 2018, 279p.

STJ. REsp 1475580/RJ. RECURSO ESPECIAL 2014/0108779-3. Relator(a) Ministro LUIS FELIPE SALOMÃO. Órgão Julgador T4 -QUARTA TURMA. Data do Julgamento 04/05/2017.

TAVARES, J. D. Orientador Kindermann, Milene Pacheco. Adoção De Crianças Refugiadas No Brasil. Monografia de conclusão de curso (UNISUL), Tubarão: Santa Catarina, 2018. Disponível em: https://www.riuni.unisul.br/handle/12345/7069. Acesso em: 17 maio 2020.

TRICANO, V. C. A nova concepção de criança e adolescente como sujeito de direitos: depoimento especial em processos judiciais no TJ/RJ. Rio de Janeiro- RJ: $1^{\circ}$ Congresso Nacional dos Direitos da Criança e do Adolescente das Seccionais da Ordem dos Advogados do Brasil, 2017.

UNICEF. A Convenção Sobre os Direitos da Criança, 1989. Disponível em: https://www.unicef.org/brazil/convencao-sobre-os-direitos-da-crianca. Acesso em: 10 jan. 2020. 
FLORENCIO, G. de C.

WATKINS, S. A. A Mary Ellen mito: Corrigindo história bem-estar da criança. Serviço Social. Ed. 35: 1990, p. 500-503.

WEBER, L. N. D. Da institucionalização à adoção: Um caminho possível? Revista Igualdade, Ministério Público Paraná, n. 9, p. 1-9, 1995.

Giovana de Carvalho Florêncio: Mestranda no Programa de Pós-Graduação em Fronteiras e Direitos Humanos (PPFDH) na Universidade Federal da Grande Dourados (UFGD). Bacharela em Direito.

Orcid: https://orcid.org/0000-0001-9814-0252

E-mail: siovanacflorencio@hotmail.com

Este periódico utiliza a licença Creative Commons Attribution 3.0, para periódicos de acesso aberto (Open Archives Initiative - OAI). 